The Lichenologist 42(4): 353-354 (2010) C British Lichen Society, 2010 doi: $10.1017 /$ S0024282910000277

\title{
Peter James - an 80th birthday tribute
}

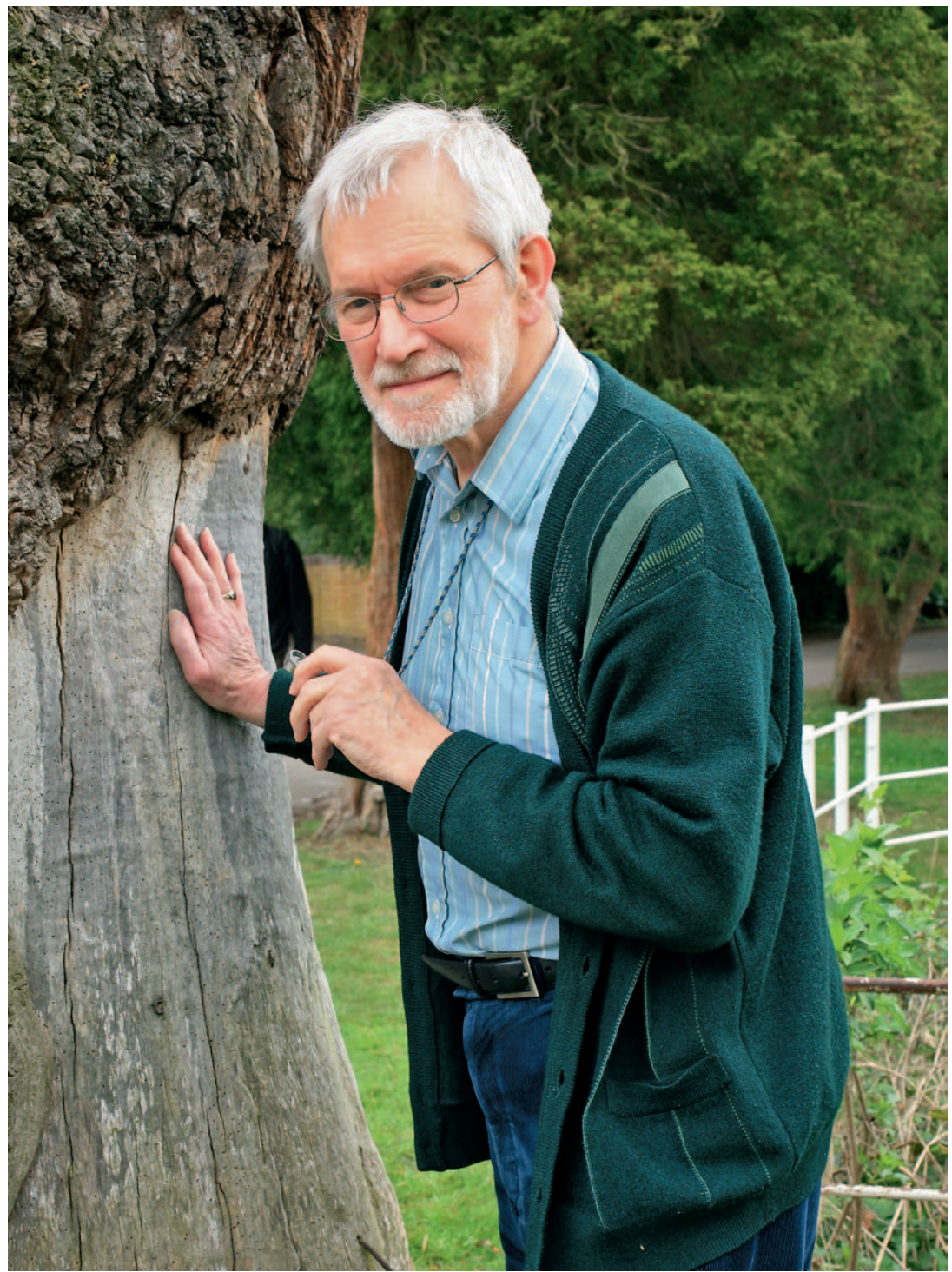

On behalf of the lichenological community worldwide, the Editors of The Lichenologist wish to congratulate Peter James on the occasion of his 80th birthday. (Photo P.D. Crittenden, taken on 28 April 2010 in Sutton Park, Sutton Coldfield, near to Peter's home, during a gathering of friends and colleagues to celebrate his birthday). 